\title{
INFLUÊNCIAS BRASILEIRAS NUM NOVO ESTILO COMUNICACIONAL Uma visão "invasora” dos «brazucas» na radiodifusão portuguesa
}

Resumo: Esse artigo tem como objetivo abordar a importância que a linguagem radiodifusora brasileira teve para a portuguesa. Na perspetiva de que a linguagem brasileira foi fundamental para o surgimento de uma dinâmica que conduziu a um novo estilo comunicacional, tanto ao nível da programação como das emissões, o artigo vem demonstrar a relação histórica da comunicação lusa com a brasileira, através da invasão «brazuqueira».

Esta invasão, que começou com a música popular brasileira, a partir da década de quarenta e provocada pelos inúmeros comunicadores brasileiros, chegados a Portugal.

Foram estes profissionais de rádio e televisão que demarcaram uma nova intensidade comunicacional, extremamente contagiante no quotidiano de todos os recetores portugueses.

Com a interferência dos «brazucas» na comunicação radiodifusora, vivenciamos uma nova postura, marco irreplicável e único no cenário deste país, trazendo uma nova imagem nos média portugueses, tocada pelas múltiplas alterações culturais, políticas e ideológicas .

Palavras-chave: Rádio; televisão, linguagem comunicacional, «brazuca».

\section{BRAZILIAN INFLUENCES IN A NEW COMMUNICATION STYLE An invasive view of «brazucas» in the Portuguese media}

\begin{abstract}
This article aims to address the importance that the Brazilian broadcasting language had for the Portuguese.
In the perspective that the Brazilian language was fundamental for the emergence of a dynamic that led to a new communication style, both in terms of programming and emissions, the article demonstrates the historical relationship between Portuguese and Brazilian communication through the "brasuqueira ».

This invasion, which began with Brazilian popular music, from the 1940s, and provoked by countless Brazilian communicators, arrived in Portugal.

It was these radio and television professionals that demarcated a new intensity of communication, extremely contagious in the daily lives of all Portuguese recipients.

With the interference of the "Brazucas" in the broadcasting communication, we experienced a new posture, an unmistakable and unique landmark in this country's scenario, bringing a new image in the Portuguese media, touched by multiple cultural, political and ideological changes.
\end{abstract}

Keywords: Radio, television, communication language, «Brazuca».

\footnotetext{
${ }^{1}$ Doutorado em Ciências da Comunicação pela Universidade do Minho (Portugal) (paulolepetri@gmail.com)
} 


\section{Uma visão "invasora” dos «brazucas» nos média portugueses}

A minha visão invasora dos «brazucas» em Portugal tem início com a chegada dos primeiros colonizadores portugueses ao Brasil e, com eles (1551), a vinda dos jesuítas (Neto e Bomura, 2008, p.177) com o seu propósito catequizador da nação indígena. Mais tarde, com a vinda da família real portuguesa (1807), firma-se um paradigma desenvolvimentista, demarcado no seu percurso histórico pelo grito independentista de D. Pedro I (1822) e, mais tarde, pelo movimento republicano do Marechal Deodoro da Fonseca, primeiro Presidente do Brasil (1889).

É neste percurso temporal que se concretiza a verdadeira génese do povo brasileiro, apoiada no tripé cultural de índios, negros e portugueses, demarcando de maneira acentuada o "autêntico ADN" do povo brasileiro.

Se, por um lado, Portugal doou de forma categórica aspetos inquestionáveis e fundamentais para a formação da cultura brasileira, como a religião, a música, a gastronomia, a valiosa mão-de-obra lusitana dos então "brasileiros de torna-viagem" (Alves,1994, p.35) nos garimpos do ouro das Minas Gerais (XVIII), no desenvolvimento da lavoura cafeeira a partir do século XIX e no progresso do comércio urbano nas principais capitais brasileiras, no começo do século XX, além, é claro, da sua representatividade histórica como país descobridor e colonizador, e do seu determinante legado, fundamental para o crescimento sociocultural do povo brasileiro: a sua língua. Da mesma forma que atribuímos o essencial legado da cultura indígena, com as suas lendas, com a sua culinária, com o seu vocabulário, com os seus costumes e com as suas práticas populares na medicina derivada das plantas (Campos, 2017, pp.33; 44; 52), assim como a forte interferência da cultura africana que, a partir de sua chegada no século XVI, influenciou de forma contundente a transmissão da sua essência cultural, através do seu ritmo musical (Santos, 2016, p.219), culinário, religioso, linguístico (Franzin, 2012) e, no meu entender, o seu valoroso espírito festivo.

Com essa fusão tem início o perfil de uma nação que emerge e se compõe na verdadeira formação do seu sincretismo (Barreto, 2008, p.480), herança valiosa de uma miscigenação, formadora da autêntica identidade de brasilidade. E é com essa identidade que Brasil e Portugal se entrelaçam, dando origem à sua inquestionável designação de "país irmão". Entre tantos motivos integradores, foi a música, no meu entender, a primeira a incorporar uma transplantação precedente das suas verdadeiras origens. Como 0 fado que é, sem dúvida nenhuma, o principal género musical português e que, de acordo com várias fontes, tem a sua origem no Brasil.

O crítico e pesquisador musical José Ramos Tinhorão (Tinhorão, 1999, p.99) e a Enciclopédia de Música Brasileira afirmam que o fado é uma derivação do Lundu (Carvalho, 2003, p.60) brasileiro. Ele surgiu no Rio de Janeiro, no fim do século XVIII, como uma dança, e com o regresso do rei D. João VI e a sua corte a Portugal, em 1821, foi o responsável pela difusão das cantigas do fado por Lisboa. Nesse momento, sem a sua coreografia dançante, apenas como canção sentimental, sob a forma de "fado português".

Da mesma forma que a Modinha que nasce no Brasil e vai para Portugal, por intermédio do cantor e compositor brasileiro Domingos Caldas Barbosa (Tinhorão,1999, p.115), voltando novamente para o Brasil, no começo do século XIX, para se caraterizar como sendo o melhor meio de expressão poéticomusical brasileiro.

Mas devemos ressaltar que tanto a Modinha e o Lundu (Caldas, 1985, p.10), quanto o próprio fado, são integrantes de uma hibridização gerada por uma cultura determinada pelo próprio expansionismo do Império Português do século XV em diante e que inegavelmente são géneros musicais que se vêm entrelaçando com a própria história da música luso-brasileira, bem como devemos 
ressaltar que só com o desenvolvimento dos primeiros centros urbanos no Brasil, a partir do final do século XIX, é que se configura a verdadeira síntese da expressão musical urbana brasileira, através do hibridismo do som de índios, negros e portugueses.

Não podemos esquecer que no percurso extensional da história, Portugal sempre esteve ativamente presente em várias esferas da sociedade brasileira, através de um multiculturalismo ramificado por vários ícones que, cobertos por uma aura resgatam o verdadeiro significado do lusitanismo, como é no caso da maior festa popular do Brasil, o Carnaval, que foi "importado" por portugueses, por volta do século XVII. Portanto, foi graças a Portugal que o Entrudo (Silva, 201, p.50) desembarcou na cidade do Rio de Janeiro, em 1641, tendo como figura emblemática dessa festa o sapateiro português José Nogueira de Azevedo Paredes, o então - Zé Pereira ${ }^{3}$. Da mesma forma, um outro ícone ligado ao Carnaval está intrinsecamente ligado aos portugueses, na forma perfeita de um produto do imaginário luso-brasileiro: a mulata, que cantada em prosas e versos fez despertar a vocação de mito sexual - obraprima do colonizador português.

Igualmente, outras importantes representações lusitanas estão hoje presentes na sociedade brasileira, como é o caso da Escola de Samba Unidos da Tijuca, a mais portuguesa de todas as escolas carnavalescas do Brasil, o glorioso Clube de Regatas Vasco da Gama, com o seu valoroso contributo para a história do futebol brasileiro, na Cidade do Rio de Janeiro, assim como a Associação Portuguesa de Desportos, na Cidade de São Paulo, além, é claro, das inúmeras comunidades portuguesas (Knopfli, 2007, p.197) espalhadas por todo o Brasil e de uma população que, ao longo dos anos, se tornou extremamente significativa perante os dois países: os luso-descendentes.

$\mathrm{Na}$ verdade, o português nunca foi visto como estrangeiro no Brasil, ele tornou-se parte de uma sociedade que, entre tapas e beijos, ao longo da sua história, se completam e se entregam no mesmo perfil de cidadania, quer pelos laços afetivos que os unem, quer pelos direitos da própria constitucionalidade que, a partir da era Vargas (1930-1945), veio beneficiar a entrada dos portugueses no Brasil.

Se a Constituição de 1934 limitava as quotas de entrada para estrangeiros de todas as nacionalidades no país, a Constituição de 1938 suspendia essa lei apenas para portugueses. Entre 1939 e 1945, houve uma redução da imigração em todo o mundo devido à Segunda Guerra. Durante o conflito mundial, Getúlio Vargas (Melo, 2014, p.443) enviou circulares para os serviços diplomáticos do exterior, dizendo que os portugueses poderiam entrar no Brasil, elegendo uma condição jurídica especial para eles, perante o Art. 129, IV, da Constituição de 1946, onde estabelece que são brasileiros "os naturalizados pela forma que a lei estabelecer, exigidas a eles (aos portugueses) apenas a residência no país por um ano ininterrupto, idoneidade moral e sanidade física" (Isabelle, 2013, 15719).

Mais tarde, os direitos e privilégios dos portugueses são mantidos nas constituições de 1967 e 1969. E, tratando-se de nações irmãs, a última Constituição Brasileira de $1988^{4}$ segue com os mesmos privilégios aos portugueses, dando-lhes uma situação jurídica mais favorável que todos os demais estrangeiros.

\footnotetext{
${ }^{3}$ A figura do "Zé Pereira" era o sapateiro português José Nogueira de Azevedo Paredes que, num Carnaval, por volta de 1850, reuniu amigos e agitou as ruas do Rio de Janeiro ao som de bombos, zabumbas e tambores. Era o que faltava para a popularização definitiva dos festejos na cidade, e o início de uma metamorfose que transformaria não apenas o Carnaval, mas toda a música brasileira. No ano seguinte já havia vários imitadores do "Zé Pereira". As primeiras sociedades carnavalescas também abriram as portas para o novo costume. O Zé Pereira viraria até espetáculo teatral ("Zé Pereira Carnavalesco"), em 1869 pelo ator cómico Francisco Correia Vasques (1839-1892). (Lorenzo, 2004), 04,10,16.
} 
Não podemos deixar de mencionar que a imigração portuguesa para o Brasil, do início da sua colonização até ao início do século XX, deixou traços permanentes na evolução da sociedade brasileira, da mesma forma que, em meados desse mesmo século, esse número de imigrantes portugueses decresceu acentuadamente, começando a surgir, em finais da década de 70, um movimento inverso, no qual os brasileiros, na sua maior parte luso-descendentes, na busca por melhores condições de vida, "invadiam Portugal".

No meu entender, o grande responsável por essa invasão «brasuqueira» em Portugal, muito antes dos finais dos anos 70, foi o veículo rádio que, por volta do final da década de trinta até o começo dos anos 60, começou a propagar, com enorme sucesso, as então marchinhas carnavalescas (Severiano e Mello, 1997, p.19), oriundas das companhias de teatro de revista brasileiras que se apresentavam em Lisboa e no Porto ${ }^{5}$. Aliás, sobre as marchinha carnavalescas, devemos ressaltar que elas chegaram ao Brasil pelos portugueses (Caldas. 1985, p.45) e se caracterizam pela mistura da marcha portuguesa com ritmos das marchas militares, embora com um ritmo mais acelerado, com letras picantes e com um duplo sentido.

Sem dúvida nenhuma, o veículo rádio foi o grande divulgador da Música Popular Brasileira (MPB) em Portugal. Responsável pela divulgação de vários compositores e intérpretes, como Chico Buarque, Maria Bethânia, Joana, Ivan Lins, Milton Nascimento, Djavan, entre muitos outros, e também pelos inúmeros movimentos musicais brasileiros, como o da Bossa Nova de João Gilberto, Tom Jobim e Vinícios de Morais, a jovem Guarda do Rei Roberto Carlos, passando pelo Tropicalismo de Caetano Veloso, Gal Costa e Gilberto Gil, ao Samba de Zeca Pagodinho, Seu Jorge e Alcione, a acensão da música sertaneja de Chitãozinho e Chororó, Leandro e Leonardo ao cantor Teixeirinha que, em meados dos anos 60, foi eleito pela crítica como o cantor de maior vendagem de discos em Portugal, interpretando a música "Coração de Luto".

Na linha histórica radiofónica, brasileira e portuguesa, as semelhanças esbarram-se na ação dos seus protagonistas, a sua evolução ecoa, dimensionando, nas ondas emissivas do rádio, o desenvolvimento gradativo de ambos os países, tendo como início o vanguardismo do português Abílio Nunes dos Santos e a sua CT1AA (Santos, 2005, p.110), pelos brasileiros Edgard Roquete-Pinto e Henry Moritze (Moreira, 2000, p.21), com a Rádio Sociedade do Rio de Janeiro, marcos radiodifusores, na década de 20, protagonistas dos primeiros passos de um percurso de grandes desafios e apaixonantes conquistas, de lutas incansáveis, quer pelas dissonâncias programáticas dos seus governos, quer pela esperança dos seus entusiastas na luta por um meio de comunicação de massas para todos, quer pela sua elitização generalizada e pelo alto valor dos aparelhos receptores, inacessível a boa parte da população, quer pela dificuldade da sua aquisição, quer também por uma burocracia sem precedentes, através das taxas pagas às emissoras e também ao governo, quer por uma programação que, na altura, já não correspondia mais à expectativa do gosto popular.

Uma década depois, brasileiros (Brittos, 2002, p.102) e portugueses (Santos, 2005, p.170) assistem à popularização e à proliferação das emissoras de rádio, ao seu desenvolvimento técnico e ideológico, assim como à sua regularização programacional, à expansão das suas emissões, à organização dos conteúdos transmitidos, bem como à forte legislação regulamentada e atribuída pelo Estado (Moreira,

\footnotetext{
${ }^{5}$ Algumas marchinhas carnavalescas que fizeram sucesso: "Mamãe Eu Quero" (Vicente Paiva/Jararaca); "Olha a cabeleira do ZéZé" (Composição: João Roberto Kelly e Roberto Faissal); "Pó de Mico" (Dora Lopes/Renato Araujo/A. Souza); "Me Dá Um Dinheiro Aî" (Homero Ferreira/Ivan Glauco); "Fantasia de Toalha" (Sacomani/Arrelia/Ercílio Consoni); "Índio Quer Apito" (H. Lobo/Milton de Oliveira); "Roubaram a Mulher do Rui" (José Messias); "Vai com Jeito" (João de Barro); "Joga a Chave Meu Amor" (J. R. Kelly/J. Rui); "Cidade Maravilhosa" (André Filho) e a mais antiga delas todas "Ô abre alas" (Criada em 1889 por Chiquinha Gonzaga). (Dicionário Cravo Albin da Música Popular Brasileira, s/d) 04/11/17
} 
1998, p.30), ao surgimento dos primeiros ídolos e à chegada da publicidade e ao interesse fulcral da sua propagação emissiva por parte do governo.

Com a chegada da década de 40, Portugal e Brasil vivenciam o veículo rádio não só como um meio de entretenimento, lazer e propaganda, mas também como um importante meio de informação e de opinião pública, fundamental instrumento político-ideológico, sustentado pela força opressora da censura perante os valores de um Estado Novo, regimentado por António Oliveira Salazar e por Getúlio Vargas. Foi também uma década marcada pela evolução do crescimento tecnológico, por uma nova dinâmica programacional, pelo início do marketing publicitário e pela valorização da audiência, atingindo um patamar pelo qual a linguagem da comunicação verbal se torna uma arte, juntamente com o desenvolvimento técnico e com a propagação musical, formando assim os elementos fundamentais para uma dinamização do veículo que tinha como principais propagadores a Rádio Nacional do Rio de Janeiro (Brasil) e a Emissora Nacional (Portugal).

Com o indiscutível papel de maior meio de comunicação de massa da época, a rádio chega à década de 50 como sendo um importante instrumento na criação dos hábitos e costumes das sociedades portuguesa e brasileira. Divulgador cada vez mais abrangente, o veículo rádio evoluía tecnologicamente, levando assim a todos os cantos a música (carro - chefe da sua programação), juntamente com os modismos culturais da época, as mudanças políticas dos seus governantes, as informações jornalísticas do seu dia-a-dia, os capítulos inéditos das suas radionovelas, as locuções inflamadas que o desporto permitia, assim como as gargalhadas dos seus programas humorísticos, estimulando, tanto os Portugueses quanto os brasileiros, para o surgimento de uma nova sociedade, quer pelas práticas culturais divulgadas, quer pelo então estímulo propagado pelo consumo.

A década de 60 ficou marcada, para ambos os países, como sendo uma época criativa, que fez com que a rádio deixasse de ser um veículo de sentido único, ou melhor, só ser ouvido, passando também a deixar-se ouvir através das pessoas que, ao falarem, desenvolviam uma nova inter-relação de linguagem que, identificada, se tornava muito mais comunicativa. Outro espeto foi o incómodo causado pela censura. Se, por um lado, Portugal vivenciava, com a saída de Salazar do governo, uma nova fase radiofónica, produzindo programas de alto nível, seja humorísticos, informativos, de entretenimento, de crítica ou de prestador de serviços, o Brasil mergulhava na radicalização censória do Regime Militar e a mudança do contexto brasileiro, fazendo emergir um novo sistema de comunicação de massas que tem como ponta de lança a "era da televisão", obrigando assim, cada vez mais, à readaptação da rádio às novas condições de produção, de programação e de comercialização.

Mas a década de 70 também ficaria marcada, para ambos os países, como sendo uma época ditatorial por parte dos seus governantes: se, por um lado, o meio radiofónico foi um dos mais visados, ao mesmo tempo que o mais usado pelos regimes, foi, sem dúvida nenhuma, o meio que melhor soube servir-se do próprio regime para alcançar o seu crescimento e a sua expansão, tanto na área tecnicista como humana, desenvolvendo assim a sua capacidade de gerir, ultrapassar e superar todas as condições adversas a ele impostas. Também foi uma década que ficou marcada, para ambos os países, como um momento de eclosão, quer pelo aumento de novas estações e o desenvolvimento de novas faixas, no caso a FM, bem como na potência e no alcance de novos emissores, isso sem falarmos no surgimento das primeiras rádios clandestinas (piratas) e o importante despontar de uma nova linguagem comunicacional mais envolvente, afetiva e muita mais próxima do ouvinte.

Mas eis que chegam os anos 80 e, com eles, a grande expansão do veículo rádio, tanto em Portugal quanto no Brasil, quer pela disseminação do número de aparelhos pela população, proporcionando uma melhor cobertura do meio, quer pelo crescimento espantoso de emissoras radiofónicas e o seu 
faturamento programacional e publicitário, como também pelo seu importante papel de veículo de utilidade social.

Se, por um lado, o Brasil politicamente começava a visualizar a tão almejada abertura política, Portugal vivia o seu sonho de prosperidade com a sua adesão à Comunidade Europeia. Em ambos os países o meio radiofónico desfrutava o seu momento de transformação, quer pelos avanços da tecnologia do meio, proporcionando uma contundente expansão emissiva, quer pelo contágio de um novo formato comunicacional, através do dinamismo musical e desportivo, uma vez que foi a partir do começo dessa década que se deu uma verdadeira invasão de jornalistas, narradores e comentaristas brasileiros na rádio desportiva portuguesa, proporcionando entusiasticamente um novo formato criativo e uma nova linguagem decorrente do próprio jogo, bem como na sua programação e de uma melhor adequação das emissoras perante o seu público-alvo, fazendo com que o veículo rádio começasse a criar e a recriar através das ondas livres das emissoras piratas uma nova linguagem, um novo contágio comunicacional, abrindo assim as suas portas para a chegada da Rádio Cidade, elo fundamental da invasão brasuqueira em Portugal.

O linguajar brazuca contaminou os radiouvintes, invadindo de forma criativa e com seu modo brejeiro as ondas emissivas da rádio, proporcionando, além de um encontro cultural, o surgimento de uma nova identidade híbrida que trazia como obrigatoriedade na performance do seu discurso comunicacional brasuqueiro, a importante necessidade de "não ter medo de ser feliz".

Outro forte componente de propagação cultural brasileira em Portugal foi o cinema, com os filmes Dona Flor e seus dois maridos, de Jorge Amado, O Casamento, de Arnaldo Jabor e Xica da Silva, de Cacá Diegues. $O$ teatro também se fez presente com as peças $O$ Santo Inquérito, do autor Dias Gomes, e Barraca Conta Tiradentes, de Augusto Boal e Gianfrancesco Guarnieri, isto sem deixarmos de falar das obras literárias do escritor Jorge Amado que também em Portugal já eram muito bem aceites. Ainda como referência da migração do sotaque brasileiro, na comunicação de massas portuguesa, ressaltamos as dobragens dos desenhos animados, principalmente os da Disney, ficando assim quase impossível para qualquer português, hoje na casa dos 40 anos, tentar ouvir a voz da Branca de Neve ou do Mikey, assim como muitos outros personagens de Walt Disney, sem que estes não tenham a pronúncia do português brasileiro.

Contudo, não podemos negar que algumas das mais fortes responsáveis por toda essa "invasão brasuqueira", nos meios de comunicação de massas deste país, foram, sem dúvida nenhuma, as telenovelas que, a partir de 1977, na RTP1, com Gabriela Cravo e Canela, deu início a um ciclo migratório - cultural - brasileiro de grande impacto comunicacional, no qual teve início um percurso "telenoveleiro" que, ao longo de várias décadas, vem envolvendo, de forma imagética, toda a sociedade portuguesa, ao ponto de propor a essa mesma sociedade, além de novas expressões para a própria língua portuguesa, uma envolvente e forte vivência da cultura brasileira, principalmente no seio da classe média.

Portanto, podemos afirmar que a então "infiltração" da linguagem brasileira nos média portugueses, a partir do final dos anos sessenta, como ponto de partida para o surgimento, nos anos oitenta, de um novo estilo comunicacional, tanto ao nível da programação como ao nível emissivo, dando-nos a reconhecer a forte aceitação na comunicação lusa dessa então "invasão da linguagem brazuca". Invasão que, ao longo do tempo, começou a solidificar-se na eclosão harmoniosa e miscigenadora da Música Popular Brasileira (MPB), passando mais tarde a ser estimulada pelos inúmeros comunicadores brasileiros, entretanto chegados a Portugal. Inevitavelmente, dos locutores musicais aos narradores desportivos, passando pelos programas televisivos de humor, até chegarmos ao 
cinema, ao teatro, e por que não, à literatura e, por fim, ao reconhecimento consagrador das telenovelas, houve um percurso, formatado por uma quase Babel linguística - cultural brasuqueira que foi propagado pelos inúmeros profissionais que, de certa forma, proporcionaram entre nós uma nova intensidade comunicacional, extremamente transmissiva, potencialmente envolvente, de maneira a nos oferecerem um novo momento paradigmático no quotidiano de todos os portugueses.

Mas, afinal, quem é esse brazuca "invasor"?

$\mathrm{Na}$ verdade, o brazuca é o lado diacrónico de uma nova linguagem comunicacional que, propagado, nos faz entender a amplitude do seu sentido aurático que, regido por importantes características como o sentimento de felicidade, conjugado com um pouco de irreverência e muita simpatia, desenha um perfil inquestionável de brasilidade, juntamente com a palavra esperança que, equalizadas na medida certa, prescrevem o antídoto eficaz contra todos os obstáculos.

No meu entender, o brasuquismo também pode ser visto como um "sintoma quase epidémico" que prolifera entusiasticamente em quem com ele tiver contato. Provido de um grande senso de humor, aliado a uma espontaneidade incontestável, o brazuca faz de um dos seus sintomas naturais, a alegria, um estilo próprio de vida. Ele é por si só um ser falante que procura, através da comunicação humana, os sinais vitais para o relacionamento social. É cordial por natureza, lúdico por afirmação e um gozador por necessidade. É um otimista, um amante da própria vida que, segundo o escritor Millôr Fernandes, pode ser visto como sendo "um cara nascido metade no Rio de Janeiro e a outra metade em Minas Gerais, no Ceará, na Bahia, em São Paulo, sem falar em todos os outros Estados Brasileiros, sobretudo o maior deles: o estado de espirito" (Fernandes, 1978, p. 50).

Mais é importante novamente ressaltar que a visão invasora dos brazucas é um resgate que tem início no Brasil, com a chegada dos primeiros colonizadores portugueses e com eles, a vinda dos jesuítas com o seu propósito catequizador, com a chegada da família real portuguesa, pelo grito independentista de D. Pedro I e pelo movimento republicano do Marechal Deodoro da Fonseca. Mais tarde, através do seu começo elitista radiodifusor, com os fundadores da Rádio Sociedade do Rio de Janeiro, Edgard Roquette Pinto e Henry Moritze, estabelecendo a mudança de uma missão educadora de uma cultura ilustrada. O mesmo que ocorreu, a partir de 1925, na cidade de Lisboa, através da CT1AA, de Abílio Nunes dos Santos, caracterizando a institucionalização do veículo rádio pela sociedade portuguesa.

Muito mais que a então chamada "invasão dos brazucas", "Portugal e Brasil são inseparáveis por razões históricas; pela língua portuguesa; pelo mar que une as duas margens do seu coração comum; pelas afinidades tão profundas e tão intensas quanto o sangue que corre nas veias dos dois povos irmãos" (Correia. 2015, p.102).

Na verdade, essa ligação nada mais é do que a sedimentação de uma continuidade extensional, através do fluxo e refluxo migratório, quer pelas caravelas do colonizador ou pelas asas dos aviões da TAP, numa forte integração absorvida entre esses dois países que, cada vez mais, vão incorporando e compondo, na medida certa, novos momentos, quer pela herança do descobridor, contribuição portuguesa fundamental na civilização brasileira, quer agora pelo ecoar de uma pseudo invasão de uma nova linguagem, que não foi doce nem bárbaro, referenciando a letra e música tropicalista de Caetano Velos ${ }^{6}$ mais sim, determinante pela égide de seu importante legado vivido intensamente pela sua própria história.

\footnotetext{
${ }^{6}$ Gravado ao vivo e lançado em outubro de 1976, "Doces Bárbaros" é um álbum duplo, no formato de vinil, com dezessete canções distribuídas em dezoito faixas. Tecnicamente traz gravações sujas, com várias deficiências. É um trabalho único nas carreiras de Gal Costa, Maria Bethânia, Gilberto Gil e Caetano Veloso. O repertório é quase todo de autoria de Gilberto Gil e Caetano Veloso.
} 
A diferença dos Doces Bárbaros para outros grupos vocais é que as vozes não soam como uma, não constituindo arranjos harmônicos, demarcando as diferenças de cada um. Há momentos que a voz aguda e doce de Gal Costa sobressai aos demais, o mesmo acontecendo com a voz grave de Maria Bethânia, sendo as de Gilberto Gil e Caetano Veloso as que mais se confundem em uma só. Gal Costa é a voz do grupo, o centro intocável, docemente bárbara.

O primeiro disco traz apenas sete canções, longas, divididas em dois lados. "Os Mais Doces Bárbaros" (Caetano Veloso) abre a aventura musical. Alegre, já de início estabelece a proposta do álbum, com as quatro vozes explodindo as suas diferenças. Por mais de seis minutos é anunciada a invasão bárbara, trazendo na mesma mensagem afoxés, orixás, sincretismo cristão, astronaves, cordões, hino flower power, numa aventura que destila ventos tropicalistas. Pela primeira vez temos uma Maria Bethânia tropicalista, movimento do qual se negara fazer parte. (Lee-Meddi, 2010.) (Janeiro de 2016) 


\section{Referências bibliográficas}

Aldé, L. (2004). O Zé Pereira. A evolução do Carnaval brasileiro. Folclore e datas importantes. Educação Pública: Fundação CECIERJ. Governo do Rio de Janeiro. Consultado em 04 outubro. 2016. Disponível em: http://www.educacaopublica.rj.gov.br/cultura/folclore/0013 04.html

Alves, F. (1993). Os brasileiros: Emigração e retorno no Porto oitocentista. Porto: Edição do Autor.

Knopfli, F. (2007). A comunidade portuguesa no Brasil. Revista População e Sociedade, 14(Parte II). Centro de Estudos da População. Economia e Sociedade. Edições Afrontamento. Consultado em 20 junho. 2017. Disponível em http://www.museuemigrantes.org/docs/memoria/emigracao\%20portuguesa\%20para\%20brasil.pdf

Barreto, L. (2008). A aculturação portuguesa na expansão e o luso-tropicalismo. Portugal: Percurso de intelectualidade. Volume I, Alto Comissariado para a Imigração e Diálogo Intercultura.

Brittos, V. (2002). Por que aconteceu aqui: O rádio em 1938 no Brasil. Biblioteca On-line de Ciência da Comunicação. Consultado em 11 dezembro. 2017. Disponível em: http://www.bocc.ubi.pt/pag/brittos-valerioradio-brasil-1938.pdf

Caldas, W. (1985). Iniciação à Música Popular Brasileira. São Paulo: Editora Ática.

Campos, A. (2017). Conhecendo as raízes culturais do Brasil. São Paulo: Editora Cultural Brasil.

Carvalho, P. (2003). A história do Fado. Lisboa: Dom Quixote.

Castagna, P. (s/d.). A Modinha e o Lundo nos séculos XVIII e XIX. Apostila do curso História da Música Brasileira. Instituto de Artes da UNESP. Consultado em 30 setembro. 2016. Disponível em https://escriturasvirreinales.files.wordpress.com/2014/04/lundum-y-modinha.pdf.

Correia, F. (2015). Entrevista concedida em 07 de outubro.

Dicionário Cravo Albin da Música Popular Brasileira, s/d. Domingos Calda Barbosa. Consultado em 10 outubro. 2017. Disponível em: http://dicionariompb.com.br/domingos-caldas-barbosa/dados-artisticos.

Dicionário Cravo Albin da Música Popular Brasileira (s/d). Marchinhas Carnavalescas. Consultado em 04 novembro. 2017. Disponível em: http://dicionariompb.com.br/marcha-carnavalesca/dados-artisticos.

Fernandes, M. (1978). Que país é este? Rio de Janeiro: Editora Desiderata.

Isabelle, S. (2013). Os direitos de nacionalidade concedidos aos portugueses à luz das constituições brasileiras. Revista do Instituto do Direito Brasileiro, 2(13). (Faculdade de Direito - Universidade de Lisboa).

Nórdica, A. (2012). Você sabe qual é a importância da cultura negra para a história do Brasil? Portal EBC. Consultado em 05 dezembro. 2016. Disponível em: http://www.ebc.com.br/infantil/voce-sabia/2012/11/voce-sabequal-e-a-importancia-da-cultura-negra-para-a-historia-do.

Lee-Meddi, J. (2010). Doce Bárbaros - Encontro telúrico da MPB. Virtuália - O manifesto digital. Consultado em 10 janeiro. 2016. Disponível em: http://virtualiaomanifesto.blogspot.pt/2010/01/doces-barbaros-encontro-telurico-nampb.html.

Melo, P. (2014). A imigração portuguesa no Brasil: Um olhar regional e de gênero nos censos populacionais de 192050. In Experiência da Primeira República no Brasil e em Portugal. Coimbra. Editora Imprensa da Universidade de Coimbra. Consultado em 20 dezembro. 2017. Disponível em: https://digitalis dsp.uc.pt/bitstream/10316.2/35885/1/A\%20experie\%cc\%82ncia_artigo18.pdf.

Moreira, S. (1998). Rádio Palanque. Rio de Janeiro: Mil Palavras.

Moreira, S. (2000). O rádio no Brasil. Rio de Janeiro: Mil Palavras.

Neto, A.; Maciel, B. (2008). O ensino jesuítico no período colonial brasileiro: algumas discussões. Educar, Curitiba, n. 31: Editora UFPR. 
Nicolay, R. (2012). O Fado de Portugal, do Brasil e do mundo: As teorias sobre a sua origem. Música, Mídia e Espaço Urbano. Contemporânea, edição 20, 2(Vol-10).

Santos, M. (2016). Contribuição do Negro para a cultura brasileira. Revista Temas em Educação e Saúde, 12(2). (São Paulo: Editora Araraquara).

Severiano, J.; Mello, Z. (1997). Canção do Tempo: 85 anos de música popular brasileira. Volume I. Rio de Janeiro: Editora 34.

Silva, M.; Conrado, J. (2011). Te conheço de outos carnavais: A linguagem das escolas de Samba nos circuitos da comunicação entre Brasil e Portugal (Tese de Doutoramento). São Paulo: Pontifícia Universidade Católica de São Paulo.

Tinhorão, J. (1998). História social da Música Popular Brasileira. São Paulo: Editora 34.

Knopfli, F. (2007). A emigração portuguesa para o Brasil. Revista População e Sociedade, 14 (Parte II). Org. Pereira, Sousa e Ismênia. Centro de Estudos da População, Economia e Sociedade. Edições Afrontamento. Consultado em 20 junho. 2017. Disponível em:

http://www.museuemigrantes.org/docs/memoria/emigracao\%20portuguesa\%20para\%20brasil.pdf. 